\title{
Evidence Based Migraine Prophylactic Drug Therapy
}

\author{
W.J. Becker
}

\begin{abstract}
Prophylactic drug therapy is a major component of overall migraine management. However, because we do not know how currently used prophylactic drugs exert their beneficial effects in migraine, their use is based primarily on clinical trials. In general, prophylactic drugs are indicated when patients have three or more attacks a month and symptomatic medication use alone is not satisfactory. The choice of drug must be individualized, and is influenced by contraindications, potential side effects, the need to treat associated symptoms like tension-type headache and insomnia, and drug cost. Whether an individual patient will respond to a given drug cannot be predicted, but there are varying degrees of scientific evidence supporting the use of each prophylactic drug in migraine. This evidence is best for metoprolol, divalproex, amitriptyline, atenolol, flunarizine and naproxen. Based on placebo-controlled crossover studies, it would appear that at least some prophylactic drugs exert the greater part of their prophylactic effects very quickly, and that these also disappear very quickly once the drug is stopped. This may not apply to all prophylactic drugs and more research is needed. More well designed clinical trials are needed to guide our use of migraine prophylactic drugs. Although clinical experience is useful, placebo responses and variations in the migraine tendency over time can make interpretation of this experience difficult. Major advances will likely only occur once the pathogenesis of migraine and the mode of action of the prophylactic drugs is better understood.
\end{abstract}

RÉSUMÉ: Traitement prophylactique de la migraine basé sur des données probantes. La médication prophylactique est un aspect important du traitement de la migraine. Cependant, parce que nous ne savons pas comment les médicaments utilisés en prophylaxie de la migraine exercent leurs effets bénéfiques, leur utilisation est basée principalement sur des essais cliniques. En général, les médicaments utilisés en prophylaxie sont indiqués quand les patients ont trois accès de migraine ou plus par mois et que l'utilisation d'une médication symptomatique seule n'est pas satisfaisante. Le choix de la médication doit être individualisé et est influencé par les contreindications, les effets secondaires potentiels, la nécessité de traiter les symptômes associés tels la céphalée de tension et l'insomnie, et le coût de la médication. Il est impossible de prédire si un patient répondra à tel ou tel médicament, mais il existe des données scientifiques de valeur inégale supportant l'utilisation de chaque médicament utilisé en prophylaxie de la migraine. Ces données sont plus probantes pour le métoprolol, le divalproex, l'amitriptyline, l'aténolol, la flunarizine et le naproxen. Il semble que, d'après les études en chassé-croisé contrôlées par placebo, certains médicaments exercent la plus grande partie de leur effet prophylactique très rapidement et que ces effets disparaissent également très rapidement quand le médicament est cessé. Cette observation ne s'applique peut-être pas à tous les médicaments utilisés en prophylaxie de la migraine et il faut faire plus de recherche sur ce sujet. D'autres essais cliniques bien conçus sont nécessaires pour guider notre utilisation de ces médicaments. Bien que l'expérience clinique soit utile, l'effet placebo et les variations dans le temps de la tendance à la migraine peuvent rendre difficile l'interprétation de ces expériences. Il est probable que des progrès significatifs ne seront accomplis que lorsque la pathogenèse de la migraine et le mode d'action des médicaments prophylactiques seront mieux connus.

Can. J. Neurol. Sci. 1999; 26: Suppl. 3-S27-S32

When lifestyle changes, migraine trigger avoidance, and acute symptomatic drug therapy are insufficient, migraine prophylactic drugs provide the next line of therapy. Many migraine prophylactic drugs are currently in use, and none of them are fully satisfactory. The recent scientific and clinical advances in acute migraine headache therapy have not been matched by corresponding progress in migraine prophylactic therapy. With regard to migraine prophylactic drug therapy, there are many more questions than answers.

From the University of Calgary, Calgary, Alberta, Canada

Reprint requests to: W J Becker, 12th Floor, Neurology, Foothills Hospital, 1403 29th Street NW, Calgary, Alberta T2N 2T9 


\section{MODE OF ACTION.}

The mechanisms whereby prophylactic drugs reduce migraine frequency are unknown. Many of the commonly used migraine prophylactic drugs (propranolol, pizotifen, methysergide and cyproheptadine) are antagonists at the $5 \mathrm{HT}_{2 \mathrm{~B} / 2 \mathrm{C}}$ receptors. ${ }^{1}$ Stimulation of this receptor, (e.g. by $\mathrm{m}$ chlorophenylpiperazine) can induce migraine-like headaches, ${ }^{2}$ so it would appear logical that antagonists at these receptors might block migraine. It has been postulated that valproate and flunarizine may produce migraine prophylaxis through their effects on ion channels, in particular calcium channels, and the effects of amitriptyline may be mediated through its effects on 5-hydroxytriptamine (5HT) and noradrenaline reuptake inhibition. ${ }^{1}$ However, all these drugs appear to have multiple actions in the nervous system and associated vascular structures, and at this time it is not known which of these actions are the important ones for migraine prophylaxis. Valproate, for example, increases brain GABA levels, alters levels of excitatory and inhibitory neurotransmitters, exerts direct effects on neuronal membranes, and affects a variety of ion channels. ${ }^{1,3}$ It is therefore unlikely that we will understand the mode of action of the migraine prophylactic drugs until more is known about the actual pathophysiology of migraine itself.

More recently, the potential importance of mechanisms involving nitric oxide and the enzyme nitric oxide synthetase in migraine pathogenesis has been stressed. Many of the commonly used migraine prophylactic drugs affect nitric oxide levels. For example, $5 \mathrm{HT}_{2 \mathrm{~B} / 2 \mathrm{C}}$ receptor stimulation liberates nitric oxide, so migraine prophylaxis by $5 \mathrm{HT}_{2 \mathrm{~B} / 2 \mathrm{C}}$ antagonists such as pizotifen and methysergide might involve this mechanism. ${ }^{4}$

\section{INDICATIONS FOR MIGRAINE PROPHYLAXIS}

There are no and hard fast rules as to when a prophylactic medication should be used. Generally speaking, prophylaxis is considered in the following clinical circumstances when a patient shows:

1. Three or more severe attacks per month that fail to respond adequately to symptomatic therapy ${ }^{5}$ or in migraine with lower frequency if disability is severe enough to warrant prophylactic therapy.

2. Contraindications to effective symptomatic medications.

3. Ineffectiveness of symptomatic medications.

4. Frequent use of abortive medications which puts the patient at risk for medication induced headache (transformed migraine). ${ }^{6}$

5. Rare headache types causing profound disruption and/or risk of neurologic injury (i.e. hemiplegic migraine). ${ }^{7}$

The advent of more effective symptomatic migraine therapies (i.e. the triptans) will no doubt reduce the proportion of migraine patients who require prophylaxis. Even though some of these new symptomatic medications are expensive, Adelman et al. ${ }^{8}$ recently pointed out that when only medication costs are considered, the more expensive prophylactic drugs such as valproate, methysergide and flunarizine become cost effective only at quite high headache rates, e.g. eight attacks per month. If however, the symptomatic medications are not completely effective in patients experiencing significant disability with their attacks, the overall cost effectiveness (time lost from work, etc.) of prophylactic drugs for the patient would rapidly improve.

\section{CHOICE OF DRUG}

Once the decision has been made with the patient to initiate migraine prophylaxis, at least six factors need to be considered in choosing the appropriate drug. These include the following:

1. Contraindications. Many of the commonly used migraine prophylactic drugs have definitive contraindications, i.e. asthma for $\beta$-blockers and a history of significant depression for flunarizine. For some patients therefore, some of the available migraine prophylactic drugs are rapidly eliminated as therapeutic options.

2. Impact of common drug side effects on patient lifestyle. A good example here would be the migraine sufferer who is also a competitive athlete. $\beta$-blockers would clearly not be tolerated in such patients because of their limiting effect on peak cardiovascular performance.

3. General drug side effects. The migraine prophylactic drugs differ in the frequency with which they produce significant side effects. In this regard, one would tend to use $\beta$-blockers and tricyclic medications before drugs like valproate and methysergide.

4. Presence of associated non-migraine symptoms. These will frequently influence the choice of prophylactic drug. For example, although $\beta$-blockers are considered by many to be drugs of first choice for migraine prophylaxis, the presence of a significant additional number of headache days per month from tension type headache, or the presence of significant insomnia may well tip the balance in favour of a tricyclic drug as a first choice for that patient.

5. Drug efficacy. This is a controversial issue, in part because many drugs have undergone insufficient good quality randomized placebo-controlled clinical trials. Some authors have divided migraine prophylactic drugs into high efficacy drugs $(\beta$-blockers, serotonin antagonists, tricyclics and divalproex) and lower efficacy drugs (calcium channel blockers, specific serotonin reuptake inhibitors, and nonsteroidal anti-inflammatory drugs). ${ }^{7}$ However, these categories can be questioned and, for example, clinical trials have shown a calcium channel blocker, flunarizine, to be as effective as $\beta$-blockers. ${ }^{9}$ In the same way, controlled trials have shown flunarizine to be as effective as methysergide in certain patient populations. ${ }^{10}$ Tolfenamic acid has shown similar efficacy to propranolol. ${ }^{11}$ It would appear that given the limitations of currently available data, the efficacy rates of the various migraine prophylactics in patient groups is not all that different. Given the poor quality of the data for some drugs, it is difficult to say whether one migraine prophylactic drug is definitely better than another in terms of efficacy.

Another important issue with regard to efficacy is how much good scientific data actually backs up the claim that a particular migraine prophylactic drug is better than placebo. Ramadan et al. ${ }^{12}$ addressed this issue in their comprehensive 
review. With their methodology they rated all randomized double-blind, placebo-controlled trials for migraine prophylactic drugs for scientific rigour on a five-point scale, with one being low and five being good. A good trial which showed that a drug was superior to placebo was given a score of +5 and a good trial which showed that a drug was not better than placebo was given a score of -5 . The scientific rigour of each study was assessed on the basis of how well studies described their methodology, the drop out rate, the sample size, the appropriateness of the statistical methods used, and how well the results were presented. Based upon this analysis, the evidence supporting the contention that a migraine prophylactic drug is better than placebo varies widely from one drug to another, depending upon the number and quality of clinical trials that have been done and whether they showed negative or positive results. For the $\beta$-blockers, for example, Ramadan et al. ${ }^{12}$ concluded that there was better quality scientific evidence supporting the use of metoprolol as compared to propranolol even though many more clinical trials have been done with propranolol, and even though propranolol is the preferred drug for a much higher percentage of neurologists in the United States than metoprolol is. The scientific scores supporting the use of a number of commonly used migraine prophylactic drugs are shown in Table 1. Neurologists might consider how much weight they wish to give to these mean scientific scores. For example, it might seem reasonable to consider first drugs with a scientific score of over two for prophylactic therapy. Other drugs might be tried later, if necessary, as a low scientific score could result solely from the fact that no high quality trials have been done with a particular drug.

Table 1: Quality of the scientific evidence supporting the use of some drugs commonly used as migraine prophylactics

\begin{tabular}{lcc} 
Drug & Numberof Trials* & Average Scientific Score \\
metoprolol & 3 & 4.3 \\
divalproex & 4 & 3.8 \\
amitriptyline & 3 & 2.3 \\
atenolol & 3 & 2.3 \\
flunarizine & 6 & 2.2 \\
naproxen & 6 & 2.2 \\
propranolol & 18 & 1.4 \\
methysergide & 3 & 1.3 \\
pizotifen & 10 & 1.1 \\
verapamil & 4 & 1.0 \\
fluoxetine & 2 & 0.0 \\
\hline
\end{tabular}

* Randomized double-blind, placebo-controlled trials

** Average of the ratings for the individual studies. A high quality study showing evidence for a prophylactic effect would be rated +5 , a high quality study showing no prophylactic effect would be rated -5 . See text for details. (from Ramadan NM, Schultz LL, Gilkey SJ. Migraine prophylactic drugs: proof of efficacy, utilization and cost. Cephalalgia 1997;17:73-80 with permission.)
6. Cost. The migraine prophylactic drugs available in Canada vary widely in cost, with the monthly cost for an average dose varying from under $\$ 10$ for propranolol and amitriptyline, to over $\$ 50$ a month for divalproex, methysergide and flunarizine. How large a factor drug cost will play in decision making will vary from patient to patient, but it would appear prudent to use low cost options first unless there is reason to do otherwise.

\section{ProphylaCtic DRUg TRIALS}

At present, it is impossible to predict which patient will respond to a particular migraine prophylactic drug. For many patients with moderate or severe migraine, it is therefore necessary to try several prophylactic drugs before meeting with success. How long each prophylactic drug should be tried before moving on to another drug is an important issue, otherwise finding the successful drug may be unnecessarily delayed.

It would appear from clinical trials data that many prophylactic drugs exert their therapeutic effect quite quickly. Steardo et al. ${ }^{10}$ found in a comparison trial of flunarizine $10 \mathrm{mg}$ and methysergide $6 \mathrm{mg}$ a day that the number of migraine attacks per month was reduced significantly from 4.3 attacks to approximately 2.2 attacks during the first month of treatment, as compared to a one-month baseline observation period. This was true even though the dose of methysergide was gradually built up during the first six days of therapy. For both drugs there was some additional reduction in the number of headache attacks per month over the ensuing four months of therapy, but this further reduction was relatively minor, with an ultimate attack rate of 1.6 headaches per month after three months of treatment.

Some of the available data would also suggest that flunarizine can have quite a rapid onset of action, even though this drug is often stated to require considerable time for its therapeutic effect in migraine prophylaxis. Sorensen ${ }^{13}$ concluded from his placebocontrolled, double-blind, crossover trial of flunarizine that "the onset of effect of flunarizine seems to be very slow, the maximum effect being attained only after three months of treatment". However, an examination of the data from that study would indicate that in fact the major part of flunarizine's prophylactic effect is evident quite quickly. At eight weeks, the difference between placebo and flunarizine in terms of migraine attacks per month was maximal, and the response at four weeks does not appear to have been analyzed during the first portion of the study. In the second limb of the study, during the first four weeks of flunarizine therapy, the migraine frequency was approximately 2.3 headaches per month in the flunarizine group, and 3.7 headaches per month in the placebo group. This difference did increase somewhat further over time, but clearly a major effect was present even during the first four weeks of treatment.

Although not placebo-controlled, a further study by Gawel et al. ${ }^{9}$ a blinded comparison of flunarizine to propranolol also showed a major reduction in migraine frequency during the first month of therapy with flunarizine, with headache frequency going from approximately 5.4 attacks per month to 3.4 attacks per month. A small further reduction in migraine frequency appeared during the second month of therapy with flunarizine, and thereafter headache frequency remained constant. 
Randomized, double-blind, placebo-controlled trials of the use of divalproex sodium in migraine prophylaxis further support the early onset of action of some migraine prophylactic drugs. In the study by Klapper et al. ${ }^{14}$ maximum reduction in migraine headache frequency from baseline had already occurred two weeks into migraine prophylactic therapy for the group receiving divalproex sodium $1000 \mathrm{mg}$ per day.

A large study by Mathew et al. ${ }^{15}$ confirmed a rapid onset of action for divalproex sodium migraine prophylaxis. By four weeks, the monthly migraine frequency had fallen from a baseline of six to four, while the placebo group had fallen from 6.3 to approximately 5.8. By three months, the monthly attack frequency had fallen further to three per month. However, it is clear from their data that the major portion of the headache reduction produced by divalproex occurred in the first four weeks of therapy, even though the dose of divalproex was being built up gradually during the first week of therapy.

It is possible that some prophylactic drugs may have a slower onset of action than others. In a propranolol/placebo comparison, Pradalier et al. ${ }^{16}$ appeared to find little treatment effect for propranolol $160 \mathrm{mg}$ per day in terms of monthly headache rate between two and six weeks of therapy, whereas between eight and twelve weeks of therapy a major effect was seen, with a mean migraine frequency of 6.4 in the placebo group and 3.2 in the propranolol group.

All the above data are derived from groups and do not exclude the possibility that individual patients might not respond to, for example divalproex, until between the second and third month of therapy. However, the data would suggest that most patients who would benefit from methysergide, flunarizine and divalproex will have shown a detectable change in their headache pattern between one and two months of therapy, and many patients will have responded sooner. A trial of two months would therefore appear adequate for most drugs, although for $\beta$-blockers, three months might be more appropriate.

\section{DURATION OF BENEFIT ONCE TREATMENT HAS STOPPED}

Double-blind, placebo-controlled, crossover trials can provide data on how long a therapeutic effect of a migraine prophylactic drug lasts once the active treatment is stopped. Clinicians do speak of stabilization of migraine, and it is stated that many patients experience continued relief after discontinuing the medication or may not need the same dose. ${ }^{7}$ However, in a clinical practice setting, where there is no placebo control, one cannot exclude other factors such as a fluctuation in the patient's migraine tendency over time. For flunarizine, Sorensen et al. ${ }^{13}$ found that in the second limb of their crossover trial, the monthly migraine frequency in their flunarizine treatment group rebounded during a one month washout from a frequency of 1.8 attacks per month to 3.2 attacks per month. The fact that this rebound carried the attack frequency of the flunarizine treatment group to a greater migraine frequency than the placebo-control group would suggest that the benefit of flunarizine had largely worn off during the one month washout period, despite the extremely long half-life of flunarizine, which is approximately 18 days. These results must be considered as inconclusive, however, because the headache frequency in the formerly flunarizine-treated group did increase somewhat further over the next few months during which time they took placebo.

With regard to valproate, data from Jensen et al. ${ }^{17}$ showed in a double-blind, placebo-controlled, crossover study that following three months of valproate therapy, the migraine days per month rose quickly during a four week washout period to levels just above those of the placebo-control group, and almost to baseline values. These data would suggest that at least after relatively short courses of prophylactic drugs (three months), the therapeutic benefit, at least for patient groups, disappears very quickly.

How quickly the therapeutic benefit dissipates after a course of prophylactic drug therapy might depend upon the drug used. Data from Kjaersgard Rasmussen et al. ${ }^{11}$ would suggest that the therapeutic benefit of tolfenamic acid (a non-steroidal antiinflammatory drug) dissipates very quickly during a four week placebo-controlled washout period, while the therapeutic benefit of propranolol appeared to largely persist during the one-month washout period.

The double-blind, placebo-controlled, crossover studies cited above might be criticized in that prophylactic drug treatment times were generally relatively short (three months). Nuti et al. ${ }^{18}$ stated that the benefits of flunarizine lasted an average of 8.4 months after discontinuation of treatment. However, this uncontrolled study compared monthly headache frequencies to baseline data, and without placebo-controlled data, it is difficult to be certain of this effect.

\section{DEGREE OF BENEFIT TO BE EXPECTED FROM MIGRAINE PROPHYLACTIC DRUG THERAPY}

For patient groups, the effect that can be expected from prophylactic drug therapy is not dramatic. For divalproex, which seems to be as effective as most prophylactics, Klapper et al. ${ }^{14}$ found that the four week migraine attack frequency was reduced by 0.5 headaches/month by placebo, and by 2.0 headaches/month by divalproex $1000 \mathrm{mg}$ (baseline headache rate approximately $5 /$ month). In other words, on average, divalproex relieved a patient in the group of 1.5 headaches per month, over and above the benefit expected from placebo. Benefits can be more dramatic, however, at the individual patient level. Forty-four percent $(44 \%)$ of divalproex treated patients had an $\geq 50 \%$ reduction in migraine attack frequency, although the placebo response was $21 \%$ for the same endpoint. To put this in perspective, $23 \%$ of divalproex treated patients were spared 2.5 headaches or more a month over and above the relief provided by placebo. There was also a trend for patients on divalproex to have a shortened headache duration, but no significant difference was observed in either the duration or the peak severity of the migraine attacks that still occurred.

In the study by Klapper et al. ${ }^{14}$ patients were excluded from entry into the study if they had failed more than two previous prophylactic drug trials. A study by Andersson et al. ${ }^{19}$ which had no such exclusion criteria and which recruited patients from three Danish neurological clinics may have included some more severely affected patients, although baseline migraine attack rates were similar in the two studies. Andersson et al. ${ }^{19}$ found that migraine attack frequency was reduced from baseline by 0.53 attacks/month by placebo (a figure very similar to that of Klapper et al.). ${ }^{14}$ In the patient group receiving metoprolol, 200 


\begin{tabular}{|c|c|c|}
\hline Study & $\begin{array}{c}\text { Baseline } \\
\text { placebo run in }\end{array}$ & $\begin{array}{c}\text { \% Reduction in migraine frequency } \\
\text { during treatment period }\end{array}$ \\
\hline Steiner et $\mathrm{al}^{20}$ & yes & 32 \\
\hline Klapper et al ${ }^{14}$ & yes & 18 \\
\hline Mathew et al ${ }^{15}$ & yes & 10 \\
\hline Steiner et $\mathrm{al}^{21}$ & yes & 10 \\
\hline Pradalier et al ${ }^{16}$ & yes & $-7 *$ \\
\hline
\end{tabular}

* Indicates $7 \%$ increase in migraine frequency

$\mathrm{mg} / \mathrm{day}$, Andersson found the migraine attack frequency was reduced by 1.3 attacks/month. Thirty-three percent $(33 \%)$ of metoprolol treated patients had a $50 \%$ or greater reduction in headache, as compared to $11 \%$ in the placebo group. These figures may not be directly comparable to the study by Klapper et al. ${ }^{14}$ as the results by Andersson for 50\% improvement were given as a reduction in the headache severity score, which included both migraine intensity and headache days, but it is noteworthy that in the divalproex study by Klapper, $23 \%$ of patients had a $50 \%$ or greater reduction in headache over and above the benefit provided by placebo, and in the metoprolol study, the corresponding figure was $22 \%$.

The results from metoprolol reported by Andersson ${ }^{19}$ included only an eight week treatment period, and headache frequencies were averaged over this entire time period. It is possible that metoprolol might have produced a greater reduction in headache if the treatment period had been extended, or even if the authors had analyzed the second four week period of their treatment period separately. Pradalier ${ }^{16}$ found that in a group of patients using propranolol $160 \mathrm{mg} / \mathrm{day}$, mean headache frequency per month was reduced to $49 \%$ of the headache frequency in the placebo group at twelve weeks. At six weeks, however, the monthly mean headache frequency was still $80 \%$ of that in the placebo group. This study suggests that it may take at least a month for $\beta$-blockers to exert a clinically significant effect in patient groups. In this study, patients were excluded if they had failed two previous prophylactic drug trials. Baseline headache frequency was six headaches/month. The study was unusual in that headache frequency was increased over baseline rates in the placebo group throughout the duration of the study.

In the clinical setting, the placebo response is included in the benefit attributed to prophylactic drug therapy. How significant is this placebo response? It can be substantial. Whether this reflects variation in migraine attack frequency over time related to seasonal or other effects, or is a true placebo response, cannot be determined from the published data. However, in a study by Steiner et al. ${ }^{20}$ in which lamotrigine was compared to placebo, the mean monthly migraine frequency was reduced by $32 \%$ in the placebo group during the third treatment month as compared to baseline, whereas the corresponding figure for the lamotrigine group was $11 \%$. In the study by Klapper, ${ }^{14}$ migraine attack frequency was reduced approximately $18 \%$ in the placebo group at three months compared to baseline. Table 2 shows the placebo response rates found in a number of representative migraine prophylactic clinical trials. As can be seen, the response rates vary widely from study to study, with one study showing an actual worsening of headache frequency in headache patients on placebo. ${ }^{16}$ In clinical practice, the "placebo rate" may be higher, as patients will know that there is no placebo. Also, in the studies listed in Table 2, placebo is given in a single-blind fashion during the four week baseline "run in" period, and therefore some lessening of headache frequency due to placebo response may well have already occurred, and been incorporated into the baseline measurement.

In summary, the current state of migraine prophylactic treatment is imperfect, with a good response limited to a relatively small proportion of patients in most placebo-controlled migraine prophylactic drug trials. In migraine prophylaxis, patients pay the price of taking daily medications, and place themselves at risk of significant side effects. A minority of these patients reap significant benefits that make this risk worthwhile, whereas for the rest, the risk is not balanced by major headache improvement.

\section{NeW MigRAINE PROPHYLACTIC MEDICATIONS}

Riboflavin has been shown to benefit some migraine sufferers in a single double-blind, placebo-controlled clinical trial. ${ }^{22}$ This is of interest as riboflavin has the potential to improve mitochondrial function, and there is evidence that some degree of mitochondrial dysfunction may exist in migraine sufferers. ${ }^{23}$ The clinical usefulness of riboflavin in migraine requires confirmation by further studies.

Divalproex sodium now has good clinical trials evidence that it can be helpful in migraine prophylaxis. Two newer anticonvulsants, gabapentin and topiramate, may also have some benefit in migraine prophylaxis, ${ }^{24}$ although from current limited data, this benefit may be less than that given by divalproex. The usefulness of anticonvulsants as migraine prophylactics is in keeping with the concept that migraine may be associated with a state of central neuronal hyperexcitability. ${ }^{25}$ The utility of these newer anti-convulsants in migraine prophylaxis requires confirmation by more double-blind, placebo-controlled clinical trials.

\section{CONCLUSION}

Much more clinical research with large well-designed clinical trials needs to be done before the prophylactic treatment of migraine will be on a sound scientific footing. The current situation is perhaps best exemplified by the following quotations from two eminent migraine treatment authorities. It has been stated that "prophylaxis should be given as monotherapy. There is no evidence of additional effects, and side effects become very marked if two prophylactic drugs are given simultaneously". 26 On the other hand, it has also been stated that "drug combinations are commonly used for patients with refractory headache disorders ... many clinicians use the combination of an antidepressant (such as a TCA or SSRI) and a $\beta$-blockers and find that they act synergistically". 7 Controversy abounds in the prophylactic treatment of migraine headache, and the evidence base for the prophylactic therapy of migraine needs urgent expansion. 


\section{REFERENCES}

1. Goadsby PJ. How do the currently used prophylactic agents work in migraine? Cephalalgia 1997; 17:85-92.

2. Brewerton TD, Murphy DL, Mueller EA, Jimerson DC. Induction of migraine-like headaches by the serotonin agonist mchlorophenylpiperazine. Clin Pharmacol Therapy 1998;43:6059.

3. Cutrer FM, Limmroth V, Moskowitz MA. Possible mechanisms of valproate in migraine prophylaxis. Cephalalgia 1997;17:93-100.

4. Olesen J, Thomsen LL, Lassen LH, Jansen-Olesen I. The nitric oxide hypothesis of migraine and other vascular headaches. Cephalalgia 1995;15:94-100.

5. Pryse-Phillips WEM, Dodick DW, Edmeads JG, Gawel MJ, Nelson $\mathrm{RF}$, et al. Guidelines for the diagnosis and management of migraine in clinical practice. Can Med Assoc J 1997;156:127387.

6. Silberstein SD, Lipton RB, Sliwinski M. Classification of daily and near-daily headaches. Neurology 1996;47:871-875.

7. Silberstein SD. Preventive treatment of migraine: an overview. Cephalalgia 1997; 17:67-72.

8. Adelman JU, Brod A, Von Seggern RL, Mannix LK, Rapoport AM. Migraine preventive medications: a reappraisal. Cephalalgia 1998;18:605-11.

9. Gawel MJ, Kreeft J, Nelson RF, Simard D, Arnott WS. Comparison of the efficacy and safety of flunarizine to propranolol in the prophylaxis of migraine. Can J Neurol Sci 1992;19:340-345.

10. Steardo L, Marano E, Barone P, Denman DW, Monteleone P, Cardone G. Prophylaxis of migraine attacks with a calciumchannel blocker: flunarizine versus methysergide. J Clin Pharmacol 1986;26:524-528.

11. Kjaersgard Rasmussen MJ, Holt Larsen B, Borg L, Sørensen PS, Hansen PE. Tolfenamic acid versus propranolol in the prophylactic treatment of migraine. Acta Neurol Scand 1994;89(6):446-50.

12. Ramadan NM, Schultz LL, Gilkey SJ. Migraine prophylactic drugs: proof of efficacy, utilization and cost. Cephalalgia 1997; 17:73-80.

13. Sørensen PS, Hansen K. Olesen J. A placebo-controlled, doubleblind, cross-over trial of flunarizine in common migraine. Cephalalgia 1986;6:7-14.

14. Klapper J, on behalf of the Divalproex Sodium in Migraine
Prophylaxis Study Group. Divalproex sodium in migraine prophylaxis: a dose-controlled study. Cephalalgia 1997;17:103108.

15. Mathew NT, Saper JR, Silberstein SD, Rankin L, Markley HG, et al. Migraine prophylaxis with divalproex. Arch Neurol 1995;52:281-286.

16. Pradalier A, Serratrice G, Collard M, Hirsch E, Feve J et al. Longacting propranolol in migraine prophylaxis: results of a doubleblind, placebo-controlled study. Cephalalgia 1989;9:247-53.

17. Jensen R, Brinck T, Olesen J. Sodium valproate has a prophylactic effect in migraine without aura: a triple-blind, placebocontrolled crossover study. Neurology 1994;44:647-651.

18. Nuti A, Lucetti C, Pavese N, Dell'Agnello G, Rossi G, Bonuccelli U. Long term follow-up after flunarizine or nimodepine discontinuation in migraine patients. Cephalalgia 1996;16:337340.

19. Andersson PG, Dahl S, Hansen JH, Hansen PE, Hedman C, et al. Prophylactic treatment of classical and non-classical migraine with metoprolol-a comparison with placebo. Cephalalgia 1983;3:207-12.

20. Steiner TJ, Findley LJ, Yuen AWC. Lamotrigine versus placebo in the prophylaxis of migraine with and without aura. Cephalalgia 1997; 17:109-12.

21. Steiner TJ, Joseph R, Hedman C, Rose FC. Metoprolol in the prophylaxis of migraine: parallel-groups comparison with placebo and dose-ranging follow-up. Headache 1988;28:15-23.

22. Schoenen J, Jacquy J, Lenaerts M. Effectiveness of high-dose riboflavin in migraine prophylaxis. A randomized controlled trial. Neurology 1998;50:466-470.

23. Barbirolli B, Montagna P, Cortelli P, et al. Abnormal brain and muscle energy metabolism shown by 3IP magnetic resonance spectroscopy in patients affected by migraine with aura. Neurology 1992;42:1209-1214.

24. Kathpal GS. Role of selected antiepileptic drugs in migraine prophylaxis. Headache 1998;38:387.

25. Welch KMA, D'Andrea TN, Barkley G, Ramadan NM. The concept of migraine as a state of central neuronal hyperexcitability. Neurol Clin 1990;8:817-828.

26. Tfelt-Hansen P, Welch KMA. General principles of pharmacological treatment. In: Olesen J, Tfelt-Hansen P, Welch KMA(Eds). The Headaches. New York: Raven Press, 1993:299303. 